\title{
Double Invagination Ileo Coeco Colic due to a Carcinoma of the Right Colon about a Case
}

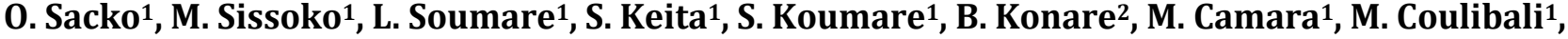 \\ S. Diallo3, B. Traore1, D. Dakouo', B. Diallo², S. Thiam¹, A. Koita1', Z. Z. Sanogo' \\ ${ }^{1}$ Surgical Department “A”, CHU Point-G, Bamako, Mali \\ ${ }^{2}$ Department of Anesthesia and Resuscitation, CHU Point-G, Bamako, Mali \\ ${ }^{3}$ Surgical Department “B”, CHU Point-G, Bamako, Mali \\ Email: ousacko72@gmail.com, ousacko72@yahoo.fr
}

How to cite this paper: Sacko, O., Sissoko, M., Soumare, L., Keita, S., Koumare, S., Konare, B., Camara, M., Coulibali, M., Diallo, S., Traore, B., Dakouo, D., Diallo, B., Thiam, S., Koita, A. and Sanogo, Z.Z. (2020) Double Invagination Ileo Coeco Colic due to a Carcinoma of the Right Colon about a Case. Surgical Science, 11, 343-346. https://doi.org/10.4236/ss.2020.1111035

Received: September 23, 2020

Accepted: November 10, 2020

Published: November 13, 2020

Copyright $\odot 2020$ by author(s) and Scientific Research Publishing Inc. This work is licensed under the Creative Commons Attribution International License (CC BY 4.0).

http://creativecommons.org/licenses/by/4.0/

\begin{abstract}
Colonic intussusception on carcinoma is rare. We report the case of an ileo-coeco-colic invagination on carcinoma of the right colon that occurred in a 40-year-old patient. The clinical symptomatology had a tendency to tumoral pathology of the colon. The ultrasound performed revealed acute intussusception. During the operation, we found an ileoceco-colic intussusception. A right hemicolectomy was performed. Anatomopathological examination of the operative specimen confirmed the diagnosis of adenocarcinoma. Conclusion: Intussusception is uncommon in adults, and is often indicative of an organic barrier to colon. His symptomatology is not very specific. Ultrasound and abdominal computed tomography help in the diagnosis. Surgical excision followed by anatomopathological examination of the operative specimen allows the diagnosis to be made histologically.
\end{abstract}

\section{Keywords}

Intussusception, Carcinoma, Hemicolectomy

\section{Introduction}

Acute intussusception (IBI) is a common pathology in children rarely seen in adults [1]. It accounts for less than $5 \%$ of acute intestinal occlusions in adults. The intaginations concern the small intestine in $75 \%$ of the cases and the colon in $25 \%$ of the cases [1]. The anatomical forms of intussusception are multiple. The ileo coecale form is the most common anatomical form. In contrast to the child, in the adult it is often secondary to an endoluminal lesion of malignant type, rarely a benign tumor [1] [2]. In adults, given its rarity, the diagnosis can 
be difficult and the circumstances of discovery vary, and the clinical picture is not specific and evolves most often in a chronic mode. We report a rare case of acute intestinal obstruction due to ileo-coecolonic invagination secondary to ascending colon adenocarcinoma in a 40-year-old patient in the surgery " $\mathrm{A}$ " department of the Point G. HUC. Following data analysis of the literature concerning this pathology, we discussed the clinical, paraclinical and therapeutic characteristics.

\section{Observation}

This patient was 40 years old, weighing $65 \mathrm{~kg}$ and $1.65 \mathrm{~m}$ tall. She was admitted on 25/7/2019 to surgery department "A" at Point-G Hospital. Pains of the right iliac fossa. The patient's recent clinical history has revealed in her antecedents a notion of chronic constipation, episodic abdominal pain, and rectorrhagia of increasing asthenia. On physical examination a mass was palpated in the right flank, the examination of the other organs was without particularity. The biological assessment was normal again. An abdominal ultrasound was requested and performed. It highlighted a suggestive aspect of acute intestinal intussusception localized to the right flank without obvious sign of complication. The patient was operated on 26/7/2019, an ileo-coeco-colic invagination on tumor of the right colon was found. We performed a right hemicolectomy (Figure 1) with transverse endo lateral iloostomy. The operative specimen was packaged and sent to the department of pathological anatomy, the result of the anatomic pathological examination concluded to adenocarcinoma.

\section{Discussion}

Intestinal invaginations are relatively rare in adults. They represent $2 \%$ to $4 \%$ of intestinal occlusions in adults [3]. The first intestinal intussusception was described by Barbette of Amsterdam in 1674 [1] and Sir Jonathan Hutchinson who performed the first intestinal intussusception surgery in 1871. Acute intussusception is defined by telescoping and penetration of an intestinal segment (invaginated loop) in the downstream segment (receiving loop) [4]. The anatomical forms of intussusception are multiple. She is most often hail (48\%-70\%), ileocolic $(25 \%-40 \%)$ and rarely pure colic (5\% - 18\%) [2] [3]. We report in this work a case of double ileal-coeco-colic invagination which represents a rare variety, some cases have been reported in the series of Sange G, and Costanzo A [5] [6]. Intestinal intussusception sites are the junction points between a mobile intestinal segment and a fixed segment such as the ileocecal region that is most frequently involved [1]. The clinical symptomatology in the adult is specific because of its rarity unlike in the child the clinical aspects are known in connection with the high frequency. It results in signs of bowel obstruction (abdominal pain, stool and gas transit stoppage) [7] and can take a chronic course (incomplete intussusception, which can regress itself.) In the series reported by Begos [8] $75 \%$ of the patients presented with signs of intestinal obstruction, and $25 \%$ of the 


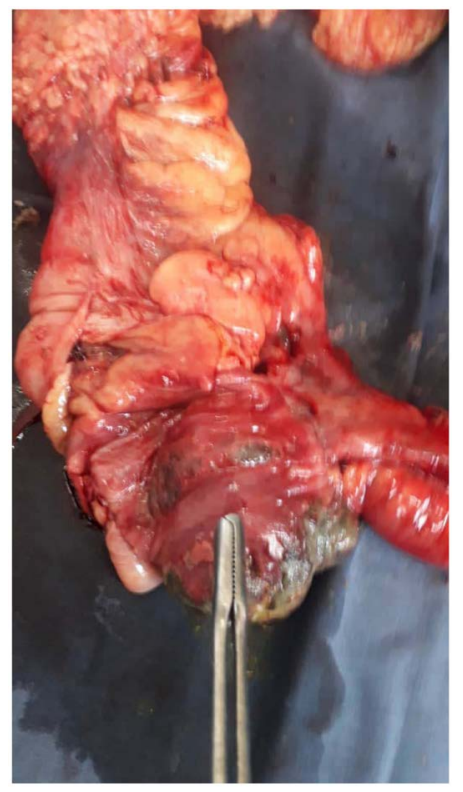

Figure 1. Colectomy patch right photo surgery "A" POINT G.

patients had an abdominal mass. The patient in our study presented with clinical signs (abdominal pain, abdominal mass, rectal bleeding, vomiting), which led us to a colonic tumor pathology. The ultrasound performed evoked an acute intussusception. The patient was operated. We found an ileoceco-colic invagination on tumor of the right colon, a right hemi colectomy with ileal anastomosis. The anatomopathological examination of the operative specimen concluded that there was adenocarcinoma of the colon and the prognosis for intussusception was related to duration of evolution, the extent of the lesions and the nature of the cause.

\section{Conclusion}

Iceo-coeco-colic invagination on colon adenocarcinoma is a rare condition in adults. Ultrasound and especially scanner have an essential place in the diagnosis of intussusception and its cause. Faced with an ileocolic invagination on colonic process, a carcinological resection is required, because the majority of colonic tumors are malignant.

\section{Conflicts of Interest}

The authors declare no conflicts of interest regarding the publication of this paper.

\section{References}

[1] Eisen, L.K., Cunningham, J.D. and Aufses Jr., A.H. (1999) Intrussusception in Adults: Institutional Review. Journal of the American College of Surgeons, 188, 390-395. https://doi.org/10.1016/S1072-7515(98)00331-7

[2] Lebeau, R., Koffi, E., Diané, B., Amani, A. and Kouassi, J.C. (2006) Invaginations 
intestinalis aigues de l'adulte :analyse d'une série de 20 cas. Annales de Chirurgie, 131, 447-450. https://doi.org/10.1016/j.anchir.2006.04.007

[3] De Moulin, D. and Paul Barbette, M.D. (1985) A Seventeenth Century Amsterdam Author of Best-Selling Textbooks. Bulletin of the History of Medicine, 59, 506-514.

[4] Boubbou, M., Idrissi, M., Chraib, M., Ibn Majdoul, K., et al. (2009) Invagination intestinale aigue chez l'adulte. Feuillets de radiologie, 49, 99-1à4. https://doi.org/10.1016/S0181-9801(09)73986-7

[5] Sange, G., Bruno, V., Urbano, D., Sammartino, S. and Mainenti, C. (1981) Ileo-Ileo-Colic Invagination due to Pure Fibroma of Intestine Observation (Authors Transl). Chirurgia Italiana, 33, 289-300.

[6] Costanzo, A., Patrizi, G., Cancrini, G., Fiengo, L., Toni, F., Solai, F., Arcieri, S. and Giordano, R. (2007) Double ileo-ileal and ileo-coecocolic intussusception due to submucous lipoma: Case Report. G Chir, 28, 135-113.

[7] Crozier, F., Portier, F., Wilshire, P., Navarro Biou, A. and Panuel, M. (2002) Diagnostic par scanner d'une invagination colocolique sur lipoma du colon gauche. Annales de Chirurgie, 127, 59-61. https://doi.org/10.1016/S0003-3944(01)00670-8

[8] Begos, D.G., Sandor, A. and Modlin, I.M. (1997) The Diagnosis and Management of Adult Intussusception. The American Journal of Surgery, 173, 88-94. https://doi.org/10.1016/S0002-9610(96)00419-9 